Измерение адаптивных ресурсов семьи является важнейшим направлением работы с семьей в условиях инклюзивной практики и основанием для психокоррекционной работы с родителями. Психологическую помощь родителям сегодня оказывают Центры диагностики и консультирования, психологопедагогической реабилитации и коррекции, с которыми должны поддерживать образовательные организации, где обучаются дети с ОВ3.

1. Кашинская О.В. Комплексное сопровождение семей, воспитывающих детей с ограниченными возможностями здоровья и инвалидностью в условиях инклюзивной образовательной организации // Вестник науки и образования. 2017. - №5 (29). - Том 2. - С 97-100.

2. Пазухина С.В., Калинина 3.Н., Декина Е.В. Психолого-педагогическое сопровождение родителей детей с ограниченными возможностями здоровья //Гуманитарные науки. - 2018. - № 2. - С.128 136.

3. Чемерилова И.А., Иванова Е.К. Исследование возможностей формирования социальнопедагогических компетенций родителей, воспитывающих детей с ограниченными возможностями здоровья, в условиях инклюзивной практики // Современная система образования: опыт прошлого - взгляд в будущее. Актуальные вопросы пенитенциарной и вузовской педагогики//Сб. науч. тр. Чебоксары: Изд-во ЧГУ, 2018. - С.161-167.

4. Чемерилова И.А., Иванова Е.К. Современная практика сопровождения семей, воспитывающих детей с ОВ3 // Мир науки, культуры, образования. - 2020. - №4 (83). - С. 203-205.

5. Чемерилова И.А., Кириллова О.В., Кириллова Т.В. Формирование компетенций родителей, воспитывающих детей с ограниченными возможностями здоровья // Глобальный научный потенциал. - № 4 (109). - С. 87-89.

\title{
Чжу Ченхуэй, Минакова Л.Ю. \\ Методы устранения влияния временных и пространственных факторов на межкультурную коммуникацию в поликультурной среде
}

Томский государственный университет (Россия, Томск)

doi: 10.18411/lj-04-2021-179

\section{Аннотация}

В статье анализируются два фактора, определяющих невербальное общение время и пространство - с точки зрения межкультурной коммуникации в процессе иноязычного общения между российскими и китайскими студентами. Подчеркивается важная роль этих двух факторов в решении проблем межкультурного барьера, возникающего в результате культурных различий. В статье выделены культурные причины этих различий, вызванные историческими и бытовыми обстоятельствами, традициями и обычаями двух стран. Учет выделенных невербальных аспектов коммуникации при реализации межкультурного общения помогает повысить его результативность. Использование метода ситуативного общения языковых партнеров позволяет снизить влияние факторов времени и пространства на межкультурную коммуникацию.

Ключевые слова: межкультурная коммуникация, невербальная коммуникация, время, пространство.

\section{Abstract}

Two factors that determine non-verbal communication - time and space - from the point of view of intercultural communication in the process of foreign language communication between Russian and Chinese students are analyzed in this paper. The important role of these two factors in solving the problems of the intercultural barrier arising as a result of cultural differences is emphasized. The article highlights the cultural reasons for these differences caused by historical and everyday circumstances, traditions and customs of 
the two countries. The highlighted non-verbal aspects of communication in the implementation of intercultural communication helps to increase its effectiveness. Situational communication method and method of language partners in teaching allow reducing the influence of time and space factors on intercultural communication.

Key words: intercultural communication, non-verbal communication, time, space.

При общении в межкультурной среде необходимо учитывать языковые особенности представителей разных стран, их различия и разнообразие приведут к трудностям в понимании и возникновению так называемых языковых барьеров. Языковые барьеры появляются наиболее часто, когда отправитель и получатель используют не только разные языки, но представляют разные культуры. Не менее часто проблемы непонимания возникают в интерпретациях следующих аспектах невербального общения: выражения лица, взгляда и визуального внимания, дистанции между людьми и проксемике, жестах и иных видах невербального поведения.

Время и пространство как факторы невербальной коммуникации оказывают уникальное влияние на межкультурную коммуникацию. Партнеры по коммуникации, принадлежащие к разным культурам, находятся в разных исторических и географических условиях и вовлечены в разную социальную действительность Возможно предположить, у них не будет одного и того же представления о факторах времени и пространства. Хун Чжао [1] считает, что концепция времени и пространства - это понимание человеком информации, передаваемой временными и пространственными факторами. Пространственно-временное представление о нормах и культуре общения постепенно формируется в течение длительного исторического периода времени и будет оставаться стабильным в течение длительного времени. В нашей статье мы уделим внимание влиянию таких факторов на коммуникацию между китайскими и российскими студентами в поликультурной среде.

Согласно теории времени Холла [2], в мире существует три культурных системы времени: специализированная система времени, формальные системы времени и неформальные системы времени. Специализированная система времени относится к отрезку времени с точностью до часа, минуты и секунды, измеренному научными методами. Система выделенного времени является авторитетной и не изменится из-за культурных различий. Следовательно, специализированная система времени мало влияет на процесс межличностного и культурного общения. Формальная система времени обычно не создает препятствий для общения людей, поскольку эта система времени является наиболее известной и используемой. Например, люди договариваются о встрече в 15:30 в пятницу. Здесь используется формальное время.

Неформальная система времени отражает культурные особенности различных социумов. Западная культура придерживается «дуалистического» образа мышления, который четко отделяет субъект от объекта. Эта философская концепция заставляет жителей Запада уделять больше внимания исследованию естественного и физического времени, что имеет большую объективность [3]. Кроме того, в западной культуре время обычно рассматривается как прямое, линейное, одностороннее, непрерывное движение. В то же время, поскольку часы были изобретены на Западе, представители данной культуры уделяли особое внимание времени с точностью до минуты и секунды, поэтому они увлеклись использованием времени для четкого структурирования своей деятельности. Такой взгляд на время часто кажется китайцам жестким и утомительным. Как отметила Wen Li [4], китайцы устраивают свое время в соответствии с реальными условиями. За исключением некоторых задач, требующих точного планирования времени, китайцы укажут только приблизительное время для выполнения большинства задач. Китайцы считают, что время циклично, а начало и конец деятельности связаны кругом. Таким образом, время - это расплывчатое понятие, которое нельзя точно 
измерить субъективно, поэтому китайцы считают, что времени достаточно, чтобы завершить свои дела или договориться о совместной деятельности.

Пример такого разного отношения ко времени мы видим в следующих диалогах.

Диалог 1: А и В: студенты из Китая

А: Хуан И, ты делал зимнее домашнее задание?

В: Еще нет.

A: Тогда я приду к тебе в субботу днем, чтобы поработать с тобой, можно?

В: Конечно, тогда я буду ждать тебя в субботу.

Диалог 2 : А: студент из Китая В: преподаватель из России

А: Здравствуйте! Валентина Ивановна. Могу я посетить вас в среду и обсудить с вами некоторые вопросы о диссертации?

В: Здравствуйте, Сун На. Хорошо, когда вы придете в офис?

А: Около 15:00, это нормально?

В: Да, нормально. Договорились.

Хуан И. в диалоге 1, безусловно, будет ждать дома честно весь день в субботу, ожидая посещения своих друзей. В диалоге 2, Валентина Ивановна может ждать дома только в оговоренное время. Причина этого в том, что русские, как представители западной культуры, следуют линейному взгляду на время. Люди, которые имеют такое представление о времени, очень ценят его. В их концепции время похоже на прямую линию, которую можно четко измерить с помощью часов или календаря. Именно из-за этой ясной концепции линейного времени россияне дорожат временем больше, чем китайцы. Следовательно, преподавателю в диалоге 2 нужно только убедиться, что она находится в офисе в оговоренное время, и что она может выйти или заняться другими делами в вне этого временного отрезка. В то время как студент из Китая способен предположить, что он сможет придти на встречу с преподавателем в любое время в среду.

Холл [5] делит использование времени в разных культурах на две категории: одна представляет собой однонаправленную систему хронирования, а другая разнонаправленную систему хронирования. Однонаправленная система хронирования рассматривает время как прямую линию, которая может быть отделена, но не может повторяться, и имеет начало и конец. Разнонаправленная систему хронирования противоположна. Время рассматривается как разбросанное. Культура многонаправленной системы обычно позволяет делать несколько разных вещей одновременно. Объективно говоря, система, принятая восточным обществом, похожа на разнонаправленную систему, тогда как западная система принимает однонаправленную систему времени.

В Китае вы можете увидеть, как продавец в магазине проверяет товар с первым покупателем, выносит товар второму покупателю и даже приветствует третьего покупателя. В Западной культуре такое распределение одновременно времени для работы с тремя разными покупателями недопустимо, человек следуют однонаправленной системе хронирования и делает только одно дело в определенную единицу времени, поэтому такой сценарий поведения продавца не появится в России.

Ориентация во времени является важной частью психологической тенденции различных культурных групп и отражает некоторые глубокие культурные коннотации. В разных культурах очень разные представления о времени, с разными приоритетами в прошлом, настоящем и будущем. Культуры с прошлой ориентацией, как правило, уделяют больше внимания традициям, старшим членам общества и положительным аспектам своей истории, сообществ или организаций и ценят их. Представители культур, ориентированных на настоящее, с большей вероятностью будут жить «в настоящий момент», сосредоточены на краткосрочных последствиях своего поведения, оценивают события, которые произошли относительно недавно, и используют недавние события для предсказания будущих событий. Наконец, люди из ориентированных на 
будущее обществ сосредотачиваются на долгосрочных последствиях своих действий и, как правило, больше сконцентрированы на таких задачах, как сбережения на будущее и отсрочка вознаграждения [6].

Пространство, как одно из факторов невербального общения, также может значительно влиять на успешность межкультурной коммуникации, и его символическое значение также чрезвычайно богато. Теория Холла показывает, что пространство может прямо или косвенно влиять на общение людей в реальности. Потребности людей в пространстве и правила общения, связанные с пространством, различны в разных культурах, например разница в расстоянии между объектами; в разных культурах ассоциации и чувства, вызванные пространственным диапазоном, также различны, например, различное отношение людей к собственной территории [7]. На качество восприятия информации пространственные факторы оказывают значительное влияние. Например, как в Китае, так и в России, если собеседники находятся близко друг к другу, то означает их отношение близки; если расстояние большое, то они более отдалены в своих взаимоотношениях. С точки зрения территории, у каждого есть своя личная территория, которую он подсознательно соблюдает, и он не любит вторжения других на нее. В то же время из-за различий в культуре, национальных условиях, обычаях представители различных лингвосоциумов по-разному воспринимает информацию, определяемую пространственным фактором. Рассмотрим отношение китайцев и россиян к разделяемому коммуникантов пространству, чтобы ощутить различия в концепциях пространства в культурах Китая и России.

(1) Отношение к скученности.

Скученность - это психологическое ощущение, которое люди испытывают, когда пространство ограничено. Люди могут чувствовать себя психологически некомфортно, потому что их личное пространство нарушается другими. Судя по отношению китайцев и русских к скученности, китайцы относительно хорошо переносят скученность. В Китае вы можете увидеть двух людей, играющих в шахматы в парке, и вокруг них будет много людей. Подобные сцены в России случаются редко.

Влияние разных мировоззрений приводит к разному отношению к скоплению людей. Понятие пространства отражает характеристику «конвергенции» в китайской культуре, но находит отражение в характеристике «дискретности» в русской культуре. Поэтому, общаясь с русскими, китайцы будут сознательно или бессознательно сокращать дистанцию (реалистичную и психологическую) друг от друга. Это показывает китайское выражение близости и дружбы, что отражается в их бессознательном стремлении сократить расстояние между коммуникантами, выражая тем самым особое расположение к партнеру по коммуникации. Подобные действия могут причинить россиянам дискомфорт и даже вызвать у них обиду. Кроме того, в традиционной китайской культуре нет понятия «частная жизнь», которое было введено западной культурой. Только в 1988 году Китай впервые сделал предварительные правовые положения о праве на неприкосновенность частной жизни в форме судебного толкования [8]. Представим различие в восприятии конфиденциальности на следующем диалоге.

Диалог 3:

А: Привет, Саша! как дела?

В: Привет, Чжао Си! Спасибо, хорошо!

А:Я слышал, ты нашёл подработку?

А: Ну. Да, нашёл.

B: Это здорово, я тоже хочу подработать. Где работаешь? Как зарплата?

A: Сейчас работаю в ресторане, и зарплата неплохая. 
На самом деле Саше бы обсуждение этих проблем не понравились. Причина межкультурного непонимания заключается в том, что восприятие китайцами частного пространства отличается от восприятия русских. Подобные проблемы, связанные с личной жизнью у китайцев, означают заботу и близость к коммуниканту и не вызовут отторжения в процессе общения. Если вы зададите россиянам вопросы, связанные с их частной жизнью, и вы с ними не знакомы, они обычно не хотят раскрывать свои проблемы подробно.

Таким образом, из приведенного выше обсуждения мы ясно понимаем, что факторы времени и пространства имеют огромное влияние на реализацию межкультурного общения, а иногда их роль даже превышает роль вербальной коммуникации. Во избежание возникновения препятствий для межкультурного общения, вызванных факторами времени и пространства, мы должны принять во внимание культурные традиции и отношения к этим двум факторам в различных лингвосоциумах, определяющим невербальную коммуникацию. Необходимо обучать студентов - представителей различных культур принимать во внимание разницу в нормах общения, обращая внимание не только на вербальную, но и невербальную коммуникацию, для того, чтобы снизить вероятность возникновения межкультурных барьеров и сделать коммуникацию максимально эффективной. По нашему мнению, рекомендуется применять следующие методы для обучения:

1. Метод ситуационного общения. Один из наиболее эффективных методов повышения межкультурной компетенции в процессе изучения иностранного языка. Преподаватели могут использовать ситуационные диалоги, сцены и задавать вопросы и задания обучающимся в процессе обучения с целью понимания разницы во времени и пространстве в восприятии между студентами из Китая и России. Разрешив эти вопросы и выполнив задания, обучающиеся смогут освоить соответствующие временные и пространственные поведенческие нормы для межкультурного общения.

2. Метод языковых партнеров. Создавая языковые партнерские отношения с иностранными студентами, постоянно вступая в контакт с ними, можно обнаруживать межкультурные различия в их повседневном общении. Этот метод часто используется в университетах иностранных языков в Китае. Его преимущество заключается в способности развивать умения межкультурного общения в местной культурной среде. Проект «Партнерская программа» Yu Yida показывает [9], метод языкового партнёра был признан большинством китайских и иностранных студентов: $37 \%$ китайских студентов очень довольны, а 52\% из них удовлетворены; 4\% иностранных студентов очень довольны и $58 \%$ из них довольны. 56\% китайских студентов считают, что они узнали в проекте, полезно для общения, а 44\% считают, что это очень полезно. После завершения проекта межкультурные знания и навыки участников в разной степени выросли, что показывает, метод осуществим. Таким образом, в российских университетах, например, на подготовительном факультете может быть применен метод языковых партнеров, чтобы студенты могли быстрее и напрямую налаживать повседневное общение с носителями языка. Эти два метода дополняют друг друга. Преподаватели могут научить обучающихся общаться в различных ситуациях за счет создания их имитации в учебном курсе. В свою очередь, обучающиеся могут сообщить преподавателю о проблемах, возникающих при общении с языковыми партнерами. На основе этого могут создаваться учебные и дидактические материалы, которые больше соответствуют реальным сценариям общения.

Таким образом, мы понимаем, как факторы времени и пространства в невербальной коммуникации влияют на эффективность межкультурной коммуникации. Чтобы избежать влияния пространственно-временных факторов на общение, использование метода ситуативного общения и метода языкового партнера в 
образовательном процессе может позволить китайским обучающимся в определенной степени понять культурные различия между двумя странами, чтобы лучше адаптироваться к русскоязычной культурной среде, тем самым снизив вероятность возникновения межкультурных барьеров в общении.

1. Хун Чжао, Факторы времени и пространства в межкультурной коммуникации Китая и России. Шанхайский международный университет исследований, 2010. - С.8 - 28.

2. Hall Edward, translated by Liu Jianrong, "Silent Language" Shanghai People's Publishing House, 1991. p. 152

3. Han Yinyan, Qian Xin, A Comparison of the Differences between Chinese and Western Time Concepts in Cross-cultural Communication, Journal of Liaoning Normal University, Vol.29 No.4 Jul. 2006. - p. 16.

4. Wen Li, Comparison of Chinese and Western Time Concepts, [Электронный ресурс] https://m.xzbu.com/9/view-988143.htm

5. Pan Guoqiang, One-Way System and Multi-Way Time System: Differences in Time Concepts Between Chinese and Western Cultures, Journal of Zhejiang Transportation College ,Vol.7 No.3 Sep. 2006. - pp. $61-63$.

6. Ashley C. Fulmer, Brandon Crosby and Michele J. Gelfand, Cross-Cultural Perspectives on Time, Psychological Press, 03.2014. - pp. 6 - 14

7. Bi Jiwan, "Cross-Cultural Nonverbal Communication" Foreign Language Teaching and Research Press, 1999. - p. 73

8. Sang Zhi, On the privacy rights of Chinese citizens, Bengbu Channel of China Court Network, 16.09.2010. [Электронный ресурс] https://www.chinacourt.org/article/detail/2010/09/id/427840

9. Yu Yi-da, Partner Program: cultivating intercultural communicative competence in native context, Journal of Jiamusi Vocational College No.1. Sum 170 2017. - pp.343 - 345.

\section{Чимаров С.Ю., Алексеев А.А. \\ Историко-педагогические аспекты формирования широты эрудиции начальствующего состава ОВД России: в контексте опыта спартанской и афинской школ воспитания}

Санкт-Петербургский университет МВД России (Россия, Санкт-Петербург)

doi: 10.18411/lj-04-2021-180

\section{Аннотация}

В статье представлен анализ основных положений спартанской и афинской систем воспитания, предопределивших формирование многих последующих научных школ, ориентированных на подготовку гармонично развитого человека в духе гражданственности и пользы своему Отечеству. Акцентируя внимание на важности учета отмеченного опыта, авторы утверждают о важности изучения истории педагогики начальствующим составом органов внутренних дел в решении задач как развития широты своей эрудиции, так и воспитания подчиненных с позиций системности данного вида педагогического воздействия и высокой требовательности за исполнение долга службы.

Ключевые слова: педагогическая мысль, история педагогики, система воспитания, античный период, традиции, широта эрудиции, органы внутренних дел.

\section{Abstract}

The article presents an analysis of the main provisions of the Spartan and Athenian educational systems, which predetermined the formation of many subsequent scientific schools, focused on the preparation of a harmoniously developed person in the spirit of citizenship and benefit to his Fatherland. Focusing on the importance of taking into account the experience noted, the authors argue about the importance of studying the history of pedagogy by the commanding staff of internal affairs bodies in solving the problems of both developing the breadth of their erudition and educating subordinates from the standpoint of 